\title{
Identification of the conditions of a mine locomotive brake system as well as its functional and morphological model with the stressed closed kinematic circuit
}

\author{
Oleksandr Koptovets ${ }^{1 *}$, Jamil Sami Haddad ${ }^{2}$, Dmytro Brovko ${ }^{3}$, Liudmyla Posunko ${ }^{4}$, and \\ Valeriia Tykhonenko ${ }^{5}$ \\ ${ }^{1}$ Dnipro University of Technology, Department of Transport Systems and Technologies, \\ 19 Yavornytskoho Ave., 49005 Dnipro, Ukraine \\ ${ }^{2}$ Al-Balqa Applied University, Department of Mechanical Engineering, Faculty of Engineering \\ Technology, Marka Ave., 11134 Amman, Jordan \\ ${ }^{3}$ Kryvyi Rih National University, Department of Building Geotechnologies, 11 Matusevycha St., \\ 50027 Kryvyi Rih, Ukraine \\ ${ }^{4}$ Dnipro University of Technology, Pavlohrad College, 63 Svitlychna Hanna St., 51400 Pavlohrad, \\ Ukraine \\ ${ }^{5}$ Dnipro University of Technology, Department of Foreign Languages, 19 Yavornytskoho Ave., \\ 49005 Dnipro, Ukraine
}

\begin{abstract}
The common tendency of mine rail haulage improvement is to increase axial power of electrical equipment traction, wagon capacity, and enhancing the speed of movement. In this context, it is typical for mine machine-building design to equip only locomotives with brake facilities. Thus, specific value of braking force of a train cannot exceed basic specific resistance to its movement. Test results of carriage rolling stock as for its braking efficiency as well as for its structural and dynamic analysis of braking mechanism have shown that a shoe-wheel brake of mine locomotives is not efficient under operation brake conditions in terms of the parametric reliability indices; hence, it is not applicable as an analogue for a trailing train part. The objective of the research is to determine a type of structural uncertainty while identifying brake conditions for adaptive control of alternative-structure tribologic system. Practical implication of the results is to determine both type and parameters of empiric dependence of brake shoe friction on a wheel tread upon the speed and braking as well as upon determination of kinetic characteristic of carriage rolling stock brake to be used in the theory of a mine train haulage to provide its safety.
\end{abstract}

\section{Introduction}

The improvement of engineering level of braking system of discontinuous haulage facilities [1-10] remains the topical problem while considering the problems of rock mass transportation [11-21] as well as materials handling both within the operating mine

\footnotetext{
* Corresponding author: koptovets.o.m@nmu.one
} 
enterprises and the ones to be founded [22 - 26].

To enhance friction characteristics of friction pairs, the world practices of the advanced brake design [27-35] use in the allied transport sectors the current solution of the adaptable material mechanics problems while applying composite ceramic-metal and asbestos-based brake shoes. However, the process does not involve the developments of adaptive structures of mechanisms, tribology, and tribomechanics to vary elastic and dissipative characteristics of brake systems on the whole. Haulage theory involves such an assumption according to which a brake gear is a rigid-segment mechanism. Moreover, it is not typical for mine rail haulage to rate frictional brake characteristics.

Contemporary research practices know [36] following factors stipulating friction forces: 1) sliding velocity; 2) specific normal pressure; 3) temperature; 4) actual contact area; 5) shape and geometry of friction surface; 6) availability of wear products; 7) elastic and viscous nature of friction surface deformation depending upon the mechanical characteristics of rubbing pair components, and being stipulated by tension modulus and shear modulus; 8) surface nature or physical condition of the rubbing pair surface layer components being defined with the help of the material density; 9) freedom of the rubbing pair components depending upon the fastening technique; 10) moisture content of the friction surface; 11) specific thermal capacity; 12) thermal conductivity; 13) thermal diffusivity; 14) heat-transfer factor; and 15) absolute viscosity coefficient. Currently, more than 13 empirical friction coefficient-sliding velocity ratios are available for the specific technical objects.

\section{Method of examination}

To achieve the purpose, it is necessary to solve statistical modeling problem characterized by following type of structural uncertainty [37]: in terms of quantity and composition of input variables within the models of brake friction force (coefficient) as output variables.

The problem is amounted to analysis in the assumption that statistical model of the object is

$$
y=\stackrel{0}{y}+\xi=\sum_{j=1}^{m} \Theta_{j} x_{j}+\xi,
$$

where $\mathrm{y}$ is the observed input variable; $\begin{aligned} & 0 \\ & y\end{aligned}$ is the non-observed component of the output variable; $\xi$ is the random value with zero mathematical expectation and finite variance; $x_{\mathrm{j}}$ is the $j$-input variable of the object of $\stackrel{0}{X \subseteq X}$ set participating in the formation of output variable of the object; $m$ is $\Theta$ number being a vector of nonzero unknown coefficients.

The problem of regression analysis has been formulated in a broad sense, i.e. it is necessary to identify which of the input $\stackrel{0}{X \subseteq X}$ variables are involved in the regression model ( $X$ is the specified set of the observed input variables; $\stackrel{0}{X}$ set is unknown). Moreover, it is required to determine the coefficient estimations within the regression models as a function of all input variables, and to evaluate prediction error in terms of the model.

Friction processes within such heavy-loaded tribological systems as a brake differ in complex interaction of performance.

Current methods of the analysis prevent from obtaining analytical output characteristics of a brake in terms of input parameters of its operational modes. The fact can explain prevalence of empiric methods while analyzing efficiency and reliability of frictional brakes. 
Study of the experiments concerning tribological systems has shown that the results obtained by different authors are controversial and incomparable.

So, changes in a friction coefficient have been first expressed by hyperbolic empiric formula. Lately, the dependence has been specified with the help of exponential type expressions, and polynomials of different degrees. Up to now, railway transport uses a dependence of friction coefficient of brake shoes upon sliding velocity and press force in a hyperbolic form. The formula type has been selected "taking into consideration all specifications and the test results taking into acount a possibility to apply the calculation in terms of the reduced friction coefficient". Institute of Machines Science has developed a law helping approximate considerable number of types of experimental dependences.

The analysis supports the idea that approximation of the experimental dependence of brake characteristics, (in particular, friction coefficient), relies upon such general prerequisite that the function assumption complies with Weierstrass theorem within a measurement interval. The theorem insists upon the idea that it is possible to sequence polynoms for a function, being continuous within the closed interval. The sequence will tend regularly to the function within the whole interval period. In this context, each researcher limits the polynomial series relying upon phenomenological ideas making the solutions unstable. Such an approach to select approximating function reflects certain viewpoint of some specialists. The function selection is beyond human potential; thus, a type of the function should be selected randomly fitting empirically the most convenient model category. Opposite viewpoint is as follows: the function type should be wellsubstantiated. The current methods of mathematical statistics and probability theory propose a definite common approach to different types of the experiment as well as representation of its results.

If it is impossible to substantiate the function type for the model development, several algebraic formulas are analyzed statistically. Such a situation is possible when a degree of the initial data and values, calculated in terms of each equation, is identical. In this context, it is impossible to prefer one of the models; hence, further analysis is to determine such an area of experimental conditions where one of the proposed models may be singled out. Environment of $(n+1)^{\text {th }}$ experiment performance is identified using discriminant analysis according to Box-Hill method [38]. Use of the method has helped us develop a mathematical model describing adequately changes in a friction coefficient $\varphi$ of shoe-wheel brake of mine locomotives depending upon velocity $V$ and force applied to the brake shoes $K$.

In this context, the initial data were analyzed with the help of four types of equations. Table 1 demonstrates the link indices for each of the groups. Adequacy measure $(R)$ prevents from the best model identification.

The experiments lasted until the probabilities of the certain $\varphi$ value obtaining differed in terms of each formula.

Hence, the linear formula:

$$
\varphi=0.731-0.202 \cdot 10^{-1} K-0.85 \cdot 10^{-1} V \pm 0.0015
$$

is the best technique to describe changes in the friction coefficient within the experimental environment $-1-3 \mathrm{~m} / \mathrm{s}$ velocity, and $4.3-11.5 \mathrm{kN}$ braking shoe pressing - which can be applied as a performance data of shoe-wheel brake of a locomotive.

The model verification in terms of $F$ criterion [38] is supported by a high convergence of the analytical values $\varphi$ and the experimental ones. 
Table 1. Statistical dependences of a brake friction coefficient.

\begin{tabular}{|c|c|c|c|c|c|c|c|c|}
\hline \multirow{2}{*}{$\begin{array}{l}\text { Test type } \\
\text { Condition of } \\
\text { the } \\
\text { contacting } \\
\text { surfaces }\end{array}$} & \multirow{2}{*}{ 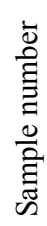 } & \multirow[b]{2}{*}{ Regression equations } & \multicolumn{3}{|c|}{\begin{tabular}{|c|c|} 
Correlation \\
indices
\end{tabular}} & \multicolumn{2}{|c|}{$\begin{array}{l}\text { Variance } \\
\text { estimate }^{*}\end{array}$} & \multirow{2}{*}{ 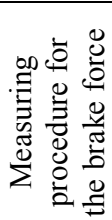 } \\
\hline & & & $\mathbb{E}$ & 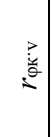 & $\stackrel{2}{a}$ & $S_{\varphi}^{2}$ & $S_{k}^{2}$ & \\
\hline \multirow{4}{*}{$\begin{array}{c}\text { Laboratory- } \\
\text { based } \\
\text { experiment. } \\
\text { No rail-wheel } \\
\text { contact has } \\
\text { been found. }\end{array}$} & \multirow{4}{*}{$\stackrel{?}{\curvearrowright}$} & $\bar{\varphi}=0.739-0.209 \cdot 10^{-3} K-0.86 \cdot 10^{-1} V$ & $\stackrel{\infty}{0}$ & $\begin{array}{l}\dot{0} \\
\dot{i} \\
\dot{1}\end{array}$ & $\stackrel{\pi}{i}$ & \multirow{4}{*}{$\begin{array}{l}\text { 官 } \\
\text { } \\
\stackrel{8}{0}\end{array}$} & 0.00018 & \multirow{4}{*}{ 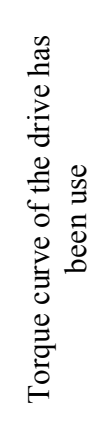 } \\
\hline & & $\begin{array}{l}\bar{\varphi}=0.805-0.278 \cdot 10^{-3} K-0.135 V+ \\
+0.59 \cdot 10^{-7} K^{2}+0.14 \cdot 10^{-1} V^{2}\end{array}$ & $\stackrel{\infty}{a}$ & ڤ̊. & $\begin{array}{ll}\nabla \\
\dot{1}\end{array}$ & & 0.00420 & \\
\hline & & $\bar{\varphi}=0.125+\frac{87.8}{K}+\frac{0.253}{V}$ & $\hat{o}$ & $\begin{array}{l}\bullet \\
\stackrel{0}{0} \\
\dot{0}\end{array}$ & $\stackrel{N}{\mathfrak{0}}$ & & 0.00097 & \\
\hline & & $\bar{\varphi}=4.44 K^{-0,358} \cdot V^{-0,393}$ & $\stackrel{0}{\circ}$ & $\begin{array}{l}0 \\
0 \\
0 \\
i\end{array}$ & $\frac{2}{i}$ & & 0.00102 & \\
\hline \multirow{3}{*}{$\begin{array}{c}\text { Industry- } \\
\text { based } \\
\text { experiment. } \\
\text { The } \\
\text { conditions } \\
\text { are typical for } \\
\text { coal mines. }\end{array}$} & \multirow{3}{*}{$\stackrel{\infty}{-}$} & $\bar{\varphi}=0.478-0.61 \cdot 10^{-4} K-0.17 \cdot 10^{-1} V$ & $\stackrel{+}{n}$ & $\begin{array}{l}\tilde{N} \\
\vdots \\
i\end{array}$ & \begin{tabular}{l}
\multirow{2}{*}{} \\
$\stackrel{0}{i}$
\end{tabular} & \multirow{3}{*}{$\begin{array}{l}\text { I } \\
\widetilde{\delta} \\
\stackrel{0}{0}\end{array}$} & 0.00067 & \multirow{3}{*}{ 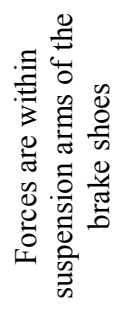 } \\
\hline & & $\begin{array}{l}\bar{\varphi}=0.557-0.202 \cdot 10^{-3} K-0.55 \cdot 10^{-1} V+ \\
+0.153 \cdot 10^{-6} K^{2}+0.87 \cdot 10^{-2} V^{2}\end{array}$ & $\begin{array}{l}\text { రె } \\
\dot{0}\end{array}$ & $\begin{array}{l}\tilde{N} \\
\stackrel{1}{1}\end{array}$ & $\begin{array}{l}\text { J } \\
\stackrel{+}{i}\end{array}$ & & 0.00918 & \\
\hline & & $\bar{\varphi}=0.342+\frac{17.8}{K}+\frac{0.661}{V}$ & $\begin{array}{l}\stackrel{t}{b} \\
\dot{0}\end{array}$ & 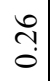 & 苍 & & 0.00125 & \\
\hline
\end{tabular}

${ }^{*} S_{\varphi}^{2}=\frac{1}{n-1} \sum\left(\varphi_{\mathrm{i}}-\bar{\varphi}\right)^{2}, \bar{\varphi}=\frac{1}{n} \sum_{1}^{n} \varphi_{\mathrm{i}} ; S_{\mathrm{k}}^{2}=\frac{1}{n-2}\left(\varphi_{\mathrm{i}}-\hat{\varphi}_{\mathrm{i}}\right)^{2}, \hat{\varphi}_{\mathrm{i}}$ are the values calculated in terms of $k^{\text {th }}$ equation $(k=1,2,3,4)$. After a point, correlation indices contain indices of the fixed factors.

Stability of the brake friction coefficient is $\alpha_{s t}=\frac{\varphi_{\text {ave }}}{\varphi_{\max }}=0.7496 \%(R=0.96)$ of which is determined by the load mode and the velocity mode.

In this context, the experiment plan involved sampling resulting from full-scale brake rig tests and brake performance tests. Current values of friction coefficient have been determined using Amonton-Coulomb formula; friction force and normal pressure of a brake shoe have been identified by means of direct measurements.

High-intensity dropping friction kinetic characteristic takes place for a shoe-wheel break of mine locomotives which needs of the friction force control within a braking mechanism. Mathematical friction theory does not consider friction force dependence upon the sliding velocity.

Being a tribological system, a brake has a type of structural uncertainty in terms of the number of input variables and their composition within the models of friction force (coefficient) as output variables. 


\section{Results and discussion}

The majority of engineering mechanisms have been designed on the basis of Assur structural groups or Assur kinematic chains where static certainty as well as kinematic certainty is their specific feature [39].

In the context of braking mechanisms of wheel pairs, supporting force of a shoe one is used as a brake pressure for a shoe two. 3-4 brake gear ratio is specified for stock locomotives.

Gear design transfers similar brake pressure within the braking mechanisms of wheel pairs determined by a drive force, ratio, and geometry of a wheel mounting. Such pressure is assumed as the constant one while calculating gear components and brake force. In terms of one-and two-cabin control, brake gears are reduced to a kinematic scheme (Fig. 1, a) being a mechanism with one driving member.

$a$

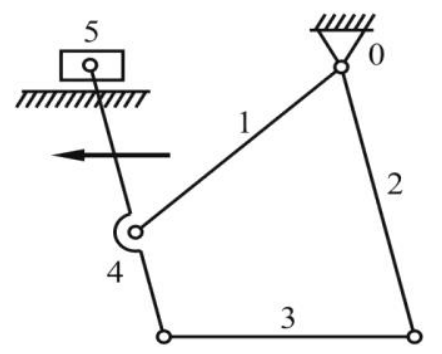

$b$

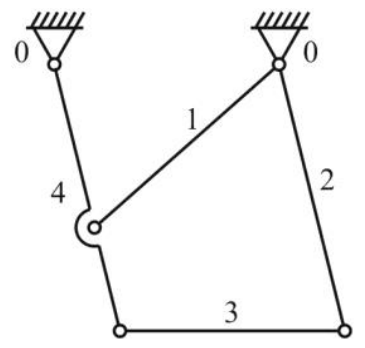

Fig. 1. Kinematic chains of a brake gear: 0 -immovable segment; $1-5$ - movable segments.

Consequently, brake gear of mine locomotives relies upon a band complex closed kinematic chain with six segments; five of them are movable segments. Relative to the immovable member (i.e. the fixed member), number of degrees of freedom of the chain is $W=1$.

When shoes are being pressed to wheels, a sliding piece (i.e. drive screw) 5 becomes immovable. In this context, a gear looks like a kinematic scheme (Fig. 1, b) which degree of freedom is $W=0$. The abovementioned provides braking shoe pressure.

Hence, brake gear is an unstable structure mechanism losing its mobility when brake mechanism is being activated. If $W=0$, then changes in a wheel reaction on a shoe pressure results in the deformation of segments 3 and 0 (Fig. 1,b) or in a wheel-shoe contact brakeage.

Changes in shoe reaction are constant due to the wear of friction pair; it is periodic due to the action of wheel geometry and oscillations of spring nodes. The abovementioned is the reason of unstable input characteristics of braking mechanisms (brake pressure) and output ones (braking force, velocity etc.).

Instability of output brake characteristics determines its parametric reliability (braking force is its index) and the locomotive on the whole (braking path). According to [40], it is required to preserve the specified performance criteria, called parametric reliability, within the preset limits. Locomotive friction coefficient $\psi_{p}$ at the braking start and friction coefficient $\psi$ at the braking finish are:

$$
\psi_{p}=\frac{B\left(K, V=V_{s t}\right)}{P_{c t s}} ; \psi=\frac{B(K, V=0)}{P_{c t s}},
$$

where $B$ is the brake force; $P_{c t s}$ is the adhesive weight; $K$ is the brake pressure; and $V$ and $V_{s t}$ are the wheel slip velocity relative to a shoe; the current value and value at the braking 
start respectively.

Thus,

$$
\psi_{p}=\psi=\frac{B\left(K, V=V_{s t}\right)}{B(K, V=0)},
$$

taking into consideration velocity characteristic of the brake friction

$$
\psi_{p}=\psi\left(1-\frac{a_{2} V_{s t}}{a_{0}-a_{1} K}\right),
$$

where $a_{0}, a_{1}$, and $a_{2}$ are the parameters of friction characteristic.

We get $\psi_{p}=0,47 \psi$ for $V_{s t}=3 \mathrm{~m} / \mathrm{s}$ and $K=12 \mathrm{kN}$; i.e. $B(V)$ exclusive of sliding while braking, $B(V)$ dependence prevents from using up to $53 \%$ of adhesive weight $P_{c t s}$.

Thus, it is necessary to control the break force in terms of $B(V)=$ const law or stabilize dependence of a brake friction coefficient upon $V$ to preserve high efficiency of breakage to stop.

Both pressure and brake force is implemented during the performance [41] in the form of a function (the basic harmonic) being close to periodic oscillations with frequency proximal to rotational velocity of a wheel pair. In this context, oscillation amplitude of the brake force is $20-34 \%$ of the average $\bar{B}$ value. Oscillation amplitude $\bar{K}$ achieves $45 \%$ $\bar{K}$. According to the measurements, average value of variations of a brake force coefficient is $k_{v}=21 \%$. It is $k_{v}=\bar{k}_{v}+\Delta k_{v}=30 \%$ taking into consideration maximum error.

Hence, average value of the brake force should be decreased by $30 \%$ from its limit in terms of adhesion to prevent wheel pairs from blocking. Its load modes should be stabilized to conserve the brake efficiency.

Traction theory knows the partial solution for a train motion equation for a braking mode:

$$
\begin{aligned}
& a_{b}=\frac{\left(b_{t}+\omega_{t}\right) g}{1000 \delta} ; \\
& b_{t}=\frac{1000 P_{c t s} \psi}{P+G_{t r}},
\end{aligned}
$$

where $a_{T}$ is the braking deceleration; $b_{t}$ and $\omega_{t}$ are the specific values of tangential of brake force and resistance to motion; $P$ and $G_{t r}$ are the weights of locomotive and train; $g$ is the gravity acceleration; and $\delta$ is the inertia factor of rotating masses.

If wheel pairs of locomotive and trailing cars are equipped with brakes, then

$$
a_{T}=\frac{\psi g}{\delta}+\frac{\omega_{t} g}{1000 \delta}
$$

In this context, the second addend is of the next lower order than the first one, the second addend can be ignored; then, we obtain $a_{T}=0.92 \mathrm{~m} / \mathrm{s}^{2}$ and $b_{t}=100 \mathrm{~N} / \mathrm{kN}$ for $\psi=0.1$ and $\delta=1.06$. We obtain $a_{T}=0.15 \mathrm{~m} / \mathrm{s}^{2}$ and $b_{t}=5.6 \mathrm{~N} / \mathrm{kN}$ for $P_{c t s}=14 \cdot 10^{4} N$ and $P+G_{t r}=250 \cdot 10^{4} \mathrm{~N}$.

Velocity of nominal motion modes of the current locomotives $V_{s t}$ is not more than $3.5 \mathrm{~m} / \mathrm{s}$; and braking deceleration for normative length of braking path $L_{s t}$ will be

$$
a_{T}=\frac{V_{s t}^{2}}{2\left(L_{s t}-V_{s t} t_{P}\right)},
$$

where $t_{p}$ is the time to prepare brakes for their action. 
$a_{T}=0.23 \mathrm{~m} / \mathrm{s}^{2}$ deceleration is for $V_{s t}=3.5 \mathrm{~m} / \mathrm{s}, L_{s t}=40 \mathrm{~m}$, and $t_{P}=4$.

If gradient of the way is equal to the specific tractive resistance, expression (6) helps calculate adhesion weight of the train:

$$
P_{c t s . p}=\frac{a_{T}\left(P+G_{s t}\right)}{g \psi}
$$

where $\frac{a_{T}}{g \psi}$ is the part of the total train weight to be used for brakeage.

Specific value of break force and braking deceleration is proportional to $\psi$ :

$$
b_{t}=1000 \psi ; a_{T}=g \psi .
$$

It is possible to obtain $1-2 g$ deceleration with the help of mine locomotive traction. The total value of the specific brake force by a locomotive with the use of slipper brakes is not higher than the specific tractive resistance. In this context, braking locomotive weight is not more than $15 \%$ of the total train weight. To stop freight train at $V_{s t}=3.5 \mathrm{~m} / \mathrm{s}$ velocity, it is necessary to use up to $23 \%$ of the train weight and up to $70 \%$ at $V_{s t}=3.5 \mathrm{~m} / \mathrm{s}$ velocity.

Thus, parametric failure of a shoe-wheel brake in the form of running wheel blocking is typical for a mine locomotive; it results from the unstable characteristics of a brake operation. Such brake modes take place for any carriage rolling stock.

Brakes are controlled to solve following problems: 1) brake efficiency regulation; 2) correction of instability of the brake mechanism characteristics included in the brake design.

Ground vehicles apply so-called antislide systems (ASS) to control brakes. The systems are of complex structure (Fig. 2); they are based upon a principle of pressure modulation within a brake gear and control of impulsive loading of a brake mechanism depending upon kinematic conditions of wheels and wheel pairs.

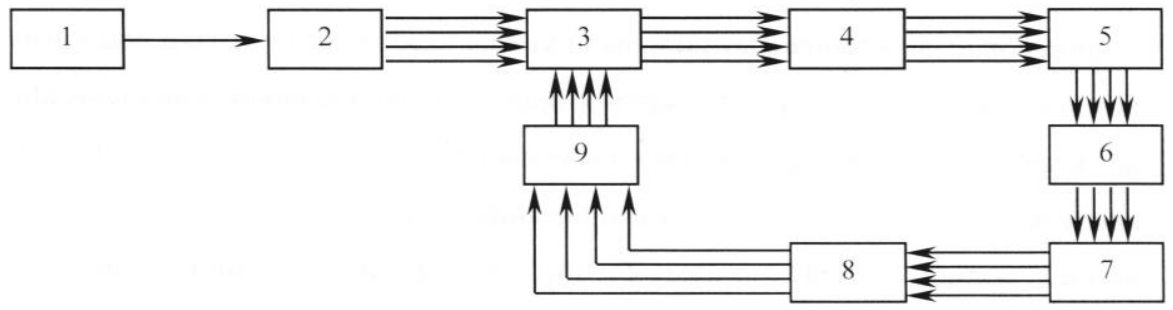

Fig. 2. Operational diagram of a brake system: 1 - foot lever or a brake control; 2 - brake cylinder or a brake switch; 3 - control valve; 4 - wheel brake cylinders; 5 - wheels; 6 - rotational-velocity sensor; 7 - microprocessor; 8 - transducer amplifier; and 9 - actuating device.

Rail industrial experiments have been carried out as for the brake equipment testing in the mode of impulsive braking pressure within the whole range of the uncontrolled loading. That is why brake gear varies the number of degrees of freedom during braking mechanism activation. It belongs to non-Assur negative-exponent structural groups, and decrements number of degrees of freedom by one [39]. Owing to their specific features, the non-Assur structures are called adaptive and indifferent kinematic structural groups.

As an adaptive structural mechanism, brake gear provides adaptability of motion laws of the driven members to the parameters of a friction procedure where the brake mechanism participates. Adapting link is a condition of shoe-wheel interaction in terms of their relation movement; it depends upon a friction procedure. A brake is an adaptive mechanism with 
the unstable structure which kinematic scheme should involve rigid segments as well as flexible, hydraulic, pneumatic, electric or other segments of another physical nature.

Currently, there are two ways to develop adaptive systems: 1) development of system of the automated control of machines and mechanisms; 2) development of adaptive mechanisms and machines as such.

A brake system with the closed kinematic configuration has indifferent connection providing the circuit stress. Indifferent mechanisms with non-Assur negative-exponent chains help develop tension along a line of structural and scheme. Static indeterminateness and load redistribution among the chain members needs the development of synthesis techniques for the closed load structures to identify normalization of frictional characteristics of a shoe-wheel brake of mine locomotives and trains.

Taking into considerations the abovementioned, it becomes necessary to define regularities of braking energy dissipation within a brake mechanism. In turn, that stipulates determination of the brake mechanism potentials as well as methods to predict frictional characteristics while tribological material producing.

\section{Conclusions}

The theoretical substantiation of the states and structure of carriage rolling stock of mine rail haulage as a mechanical system with friction has been developed.

It has been determined that shoe-wheel brake of mine locomotives has a type of structural uncertainty in terms of number and composition of input variables within the models of dependence of friction force (coefficient) as output variables. In the context of adaptive control and identification of a brake conditions it is possible to exclude unstable solutions while using all types of static analysis: dispersive, correlative, regressive, and discriminant one. Linear regressive discriminant dependence of friction coefficient of a mine locomotive brake is identified by means of load mode and speed rate being of significant instability resulting from the velocity. Brake efficiency halves during the breakage start to stop at $3 \mathrm{~m} / \mathrm{s}$ velocity; it decreases three times if velocity is $5 \mathrm{~m} / \mathrm{s}$; and it experiences its 11 times decrease in terms of a brake pressure and velocity variation.

Functional and morphological brake model has been developed according to which a brake gear belongs kinematically to negative-exponent non-Assur groups. A brake has unstable input and output characteristics of friction and braking action. A brake is an adaptive mechanism with unstable structure which kinematic scheme should involve rigid segments as well as flexible, hydraulic, pneumatic, electrical (ASS) or other segments of another physical nature being adaptive links for shoe-wheel interaction at their relative movement depending upon friction procedure parameters.

This research was partially supported by Dnipro University of Technology (Ukraine), Kryvyi Rih National University (Ukraine) and Al-Balqa Applied University (Jordan). We thank our colleagues from our institutions who provided the insight and expertise that greatly assisted the research.

\section{References}

1. Sharma, R.C., Dhingra, M., \& Pathak, R.K. (2015). Braking Systems in Railway Vehicles. International Journal of Engineering Research \& Technology, 4(01), 206-211.

2. Bureika, G., \& Mikaliūnas, Š. (2008). Research on the Compatibility of the Calculation Methods of Rolling-Stock Brakes. Transport, 23(4), 351-355. https://doi.org/10.3846/1648$\underline{4142.2008 .23 .351-355}$

3. Liudvinavicius, L., \& Lingaitis, L.P. (2007). Liudvinavičius, L., \& Lingaitis, L. P. (2007). Electrodynamic Braking in High-Speed Rail Transport. Transport, 22(3), 178-186. 


\section{https://doi.org/10.3846/16484142.2007.9638122}

4. Vernersson, T. (2007). Temperatures at railway tread braking. Part 1: Modeling. Proceedings of the Institution of Mechanical Engineers. Part F: Journal of Rail and Rapid Transit, 221(2), 167182.

5. Vernersson, T. (2007). Temperatures at railway tread braking. Part 2: Calibration and numerical examples. Proceedings of the Institution of Mechanical Engineers. Part F: Journal of Rail and Rapid Transit, 221(4), 429-441.

6. Teimourimanesh, S., Vernersson, T., Lunden, R., Blennow, F., \& Meinel, M. (2014). Tread braking of railway wheels - temperatures generated by a metro train. Proceedings of the Institution of Mechanical Engineers. Part F: Journal of Rail and Rapid Transit, 228(2), 210-221.

7. Teimourimanesh, S., Vernersson, T., \& Lunden, R. (2014). Modelling of temperatures during railway tread braking: Influence of contact conditions and rail cooling effect. Proceedings of the Institution of Mechanical Engineers. Part F: Journal of Rail and Rapid Transit, 228(1), 93-109.

8. Sharma, R.C. (2012). Recent advances in railway vehicle dynamics. International Journal Vehicle Structures \& Systems, 4(2), 52-63. https://doi.org/10.4273/ijvss.4.2.04

9. Sharma, R.C. (2011). Ride Analysis of an Indian Railway Coach using Lagrangian Dynamics. International Journal Vehicle Structures \& Systems, 3(4), 219-224. https://doi.org/10.4273/ijvss.3.4.02

10. Sharma, R.C. (2014). Modeling and Simulations of Railway Vehicle System. International Journal of Mechanical Engineering and Robotics Research, 1(1), 55-66.

11. Koroviaka, Ye., \& Lubenets, T. (2017). Substantiation of the method for constructing the diagram of the horizontal belt conveyor tightness. Mining of Mineral Deposits, 11(3), 111-116. https://doi.org/10.15407/mining11.03.111

12. Korovyaka, E.A., \& Lubenets, T.N. (2015). Substantiation of operational modes for extensible belt conveyers of mining enterprises. Zbirnyk Naukovykh Prats Natsionalnoho Hirnychoho Universytety, (49), 116-121.

13. Lubenets, M., Koroviaka, Ye., Rastsvietaiev, V., \& Lubenets, T. (2019). Improving operation efficiency of transportation vehicles equipped with a flexible tractive element under conditions of

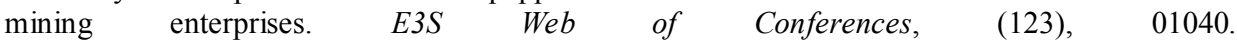
https://doi.org/10.1051/e3sconf/201912301040

14. Symonenko, V.I., Jamil Sami Haddad, Cherniaiev, O.V., Rastsvietaiev, V.O., \& Al-Rawashdeh, M.O. (2019). Substantiating Systems of Open-Pit Mining Equipment in the Context of Specific Cost. Journal of The Institution of Engineers (India): Series D. Metallurgical \& Materials and Mining Engineering. https://doi.org/10.1007/s40033-019-00185-2

15. Shustov, O.O., Haddad, J.S., Adamchuk, A.A., Rastsvietaiev, V.O., \& Cherniaiev, O.V. (2019). Improving the Construction of Mechanized Complexes for Reloading Points while Developing Deep Open Pits. Journal of Mining Science, 55(6), 946-953. https://doi.org/10.1134/S1062739119066332

16. Shirin, L., Korovyaka, Y., \& Tokar, L. (2011). Justification of design parameters of compact load-haul dumper to minen arrow vein heavy pitching deposits. Technical and Geoinformational Systems in Mining, 85-92. https://doi.org/10.1201/b11586-15

17. Sadovenko, I., Zahrytsenko, A., Podvigina, O., Dereviahina, N., \& Brzeźniak, S. (2018). Methodical and applied aspects of hydrodynamic modeling of options of mining operation $\begin{array}{llll}\text { curtailment. Solid } & \text { State } \quad \text { Phenomena, 36-43. }\end{array}$ https://doi.org/10.4028/www.scientific.net/SSP.277.36

18. Sadovenko, I.A., \& Derevyagina, N.I. (2012). About activation potential of loess landslide massif. Naukovyi Visnyk Natsionalnoho Hirnychoho Universytetu, (2), 80-84.

19. Pysmennyi, S., Brovko, D., Shwager, N., Kasatkina, I., Paraniuk, D., \& Serdiuk, O. (2018). Development of complex-structure ore deposits by means of chamber systems under conditions of the Kryvyi Rih iron ore field. Eastern-European Journal of Enterprise Technologies, 5(1(95)), 33-45. https://doi.org/10.15587/1729-4061.2018.142483 
20. Brovko, D.V., Khvorost, V.V., \& Tyshchenko, V.Yu. (2018). Qualimetric assessment in calculation of the survivability level of the mine surface objects. Visnyk Natsionalnoho Hirnychoho Universytetu, (4), 66-71. https://doi.org/10.29202/nvngu/2018-4/14

21. Andreev, B.M., Brovko, D.V., \& Khvorost, V.V. (2015). Determination of reliability and justification of object parameters on the surface of mines taking into account change-over to the lighter enclosing structures. Metallurgical and Mining Industry, 7(12), 378-382.

22. Shirin, A., Rastsvetaev, V. \& Morozova, T. (2012). Estimation of reliability and capacity of auxiliary vehicles while preparing coal reserves for stoping. Geomechanical Processes During Underground Mining-Proceedings of the School of Underground Mining, 105-108. https://doi.org/10.1201/b13157-18

23. Rastsvietaiev, V.O., Posunko, L.M., Shyrin, A.L., \& Zheglov, S.S. (2015). Estimation of factors limiting efficiency of transport schemes while preparing coal reserves in Western Donbas mines. Mining of Mineral Deposits, 9(1), 117-123. https://doi.org/10.15407/mining09.01.117

24. Rastsvietaiev, V.O. (2014). Prospects of transport and technological systems improvement during performing of mounting/dismounting operations in conditions of Western Donbass mines. Mining of Mineral Deposits, 8(2), 143-148. https://doi.org/10.15407/mining08.02.143

25. Bartashevskii, S., Koptovets, O., Novitskii, O., \& Afonin, D. (2014). Perspective ways of mine locomotives autonomy increase. Progressive Technologies of Coal, Coalbed Methane, and Ores Mining, 293-296. https://doi.org/10.1201/b17547-51

26. Shyrin, L., Koroviaka, Y., Rastsvietaiev, V., \& Denyshchenko, O. (2018). Substantiating rational parameters of a method for shrinkage ore stoping while developing thin-vein steeply inclined deposits. E3S Web of Conferences, (60), 00022.

27. Sharma, R.C. (2013). Sensitivity Analysis of Ride Behaviour of Indian Railway Rajdhani Coach using Lagrangian Dynamics. International Journal Vehicle Structures \& Systems, 5(3-4), 84-89. https://doi.org/10.4273/ijvss.5.3-4.02

28. Sharma, R. (2012). Parametric analysis of rail vehicle parameters influencing ride behavior. International Journal of Engineering, Science and Technology, 3(8), 54-65. https://doi.org/10.4314/ijest.v3i8.5

29. Sharma, R.C. (2013). Stability and Eigenvalue Analysis of an Indian Railway General Sleeper Coach using Lagrangian Dynamics. International Journal Vehicle Structures \& Systems, 5(1), 914. https://doi.org/10.4273/ijvss.5.1.02

30. Sharma, R.C., Dhingra, M., Pathak, R.K., \& Kumar, M. (2014). Magnetically Levitated Vehicles: Suspension, propulsion and guidance. International Journal of Engineering Research \& Technology, 3(11), 5-8.

31. Kumar, R., Garg, M. P., \& Sharma, R. C. (2012). Vibration Analysis of Radial Drilling Machine Structure Using Finite Element Method. Advanced Materials Research, 472-475, 2717-2721. https://doi.org/10.4028/www.scientific.net/amr.472-475.2717

32. Vashist, A., Sharma, R.C., \& Taneja, S. (2012). Productivity improvement by defect analysis in indian automobile industry. International Journal of Mechanical Engineering Research and Development, 2(2), 734-741.

33. Vashist, A., Sharma, R.C., \& Taneja, S. (2014). Productivity improvement by fixture modification. International Journal of Mechanical Engineering Research and Development, 4(3), 54-62.

34. Singla, V., Sharma, R.C., \& Singh, J. (2011). Fault diagnosis of bearing for wear at inner race using acoustic signal. International Journal of Mechanical Engineering Research and Development, 1(1), 40-46.

35. Zhang, Z. \& Dhanasekar, M. (2009). Dynamics of railway wagons subjected to braking/traction torque. Vehicle System Dynamics, 47(3), 285-307. https://doi.org/10.1080/00423110802008124

36. Khebty, M., \& Chichinadze, A.V. (1989). Spravochnik po tribotehnike. T.3. Teoreticheskie osnovyi. Moskva: Mashinostroenie, 400.

37. Sarychev, A.P. (2008). Identifikatsiya sostoyaniy strukturno-neopredelennykh system. Dnipropetrovsk: Instytut tekhnichnoi mekhaniky Ukrainy i NKA Ukrainy, 268. 
38. Mirzadzhanzade, A.Kh. (1997). Matematicheskaya teoriya eksperimenta $v$ dobyche nefti $i$ gaza. Moskva: Nedra, 165.

39. Koptovets, A.N., Shirin, L.N., Shlyahov, E.M., Denischenko, A.V., Zil, V.V., \& Yavorskaya, V.V. (2017). Modelirovanie rabochikh protsessov treniya v kolodochno-kolesnom tormoze shakhtnykh lokomotivov. Dnipro: Natsionalnyi hirnychyi universytet, 258.

40. DSTU 2862-94. (1994). Nadiinist tekhniky. Metody rozrakhunku pokaznykiv nadiinosti. Zahalni vymohy. Kyiv: Asotsiatsiia "Nadiinist mashyn ta sporud".

41. Koptovets, A.N. (2007). Experimental studies of the friction characteristics and oscillations of the brake pads taking into account the inertial, elastic and damping properties of the brake system of mine locomotives. Naukovyi Visnyk Natsionalnoho Hirnychoho Universytetu, (10), 38-42. 